\title{
Gold-Working in Ancient America
}

\author{
Warwick Bray \\ Institute of Archaeology, University of London, England \\ European observers of the fifteenth and sixteenth centuries were im- \\ pressed by both the aesthetic sensitivity and the technical virtuosity of \\ native American goldsmiths. By examining early Spanish descriptions in \\ the light of modern scientific and technical knowledge, a surprisingly \\ detailed picture of aboriginal gold technology can be built up.
}

The gold of America first came to European notice in 1492. In that year, Columbus' fleet explored the coasts of Cuba and Hispaniola and his sailors bartered Venetian glass beads, Spanish clothing, brass hawk bells and even bits of broken pottery for the golden ornaments of the natives. The West Indies were not particularly rich in precious metals but by 1530 all the major gold-producing regions of the New World from Mexico to Peru were in Spanish hands. Most of the gold jewellery was melted down on the spot but a few items were sent home as curios or as samples. The most typical reaction in Europe was astonishment at the sheer quantity of gold flowing into Spain from the new American colonies but those connoisseurs with a more discerning eye were even more amazed by the artistic quality of the pieces.

The artist Albrecht Dürer, himself the son of a goldsmith, examined part of the treasure of the Aztec emperor Montezuma when this was displayed at court in Brussels during 1520 and wrote in his notebook:
'I saw such things which were brought to the King from the
New Golden Land; a sun entirely of gold, a whole fathom
broad; likewise a moon entirely of silver, just as large; likewise
sundry curiosities from their weapons, arms and
missiles. . These things were all so precious that they were
valued at 100000 guilders. But I have never in all my days
seen anything that so delighted my heart as these things. For I
saw amazing objects and I marvelled at the subtle ingenuity of
the men in these distant lands'.

Among the host of adventurers, scholars, priests and officials who came to the New World were some who had practical experience of metalworking. Girolamo Benzoni, whose 'History of the New World' appeared in 1565, was a Milanese silversmith and jeweller, while the historian Gonzalo Fernández de Oviedo served as the king's supervisor of smelting operations in Tierra Firme (the old Spanish Main) from 1514 to 1532 . Even Sir Walter Raleigh, in his abortive search for the legendary 'Golden Citie of Manoa', collected important information about the melting and casting of gold alloys in Guyana (1).

By combining these early eyewitness accounts with modern laboratory analyses of museum specimens, it

\section{A Major Exhibition of Early American Gold}

To the native South American Indians gold was a plentiful and useful metal, not restricted to ornamental or ceremonial purposes but relied upon to make many articles for everyday use. The technical skills displayed in the fabrication of the few objects sent home by the Spanish Conquistadores in the early part of the sixteenth century astonished the artists and craftsmen of Europe, but the great majority of the gold objects were unfortunately and quickly consigned to the melting pot.

In more recent years great quantities of gold have been found in tombs in which for generations the Indians buried their dead and an immense collection of these objects has been assembled in the Museo del Oro in Bogota. Now, a representative collection of these treasures - together with others from the British Museum and private sources - will be on view to the public in a major exhibition being mounted by the Royal Academy of Arts in London from November this year until the following March under the title 'The Gold of El Dorado'.

The exhibition will amply illustrate the high level of technology displayed by the Colombian Indians, the sources of their gold, their methods of extraction and refining, their techniques of working the metal and of gilding base metals. All the technques used by the modern goldsmith, with the single exception of electroplating, had in fact been discovered and used by the Indians and the many exhibits will include examples from their major period of gold production from 400 A.D. until this vast gold culture was discovered by the Spaniards.

Dr. Warwick Bray, the author of the accompanying article, is the Academic Adviser to the exhibition. 
is possible to build up a fairly detailed picture of aboriginal gold technology as it was at the moment of European contact.

One of the best sixteenth century accounts of Indian metalsmiths at work comes from Garcilaso de la Vega, son of a Spanish father and an Inca mother. Describing the processes of melting and hammering in the Andes before the adoption of European technology, he commented:

They never make anvils of iron or any other metal. . They used hard stones of a colour between green and yellow as anvils. They planed and smoothed them against one another, and esteemed them highly, since they were very rare. They could not make hammers with wooden handles. They worked with instruments of copper and brass mixed together, and shaped like dice with rounded corners. Some are as large as the hand can grasp for heavy work; others are medium sized, others small, and others elongated for hammering a concave shape. They hold these hammers in the hand and strike with them like cobblestones. They had no files or graving tools, nor bellows for founding. Their founding they did by blowing down copper pipes half an ell or less in length, according to the size of the work. These pipes were blocked at one end, but had a small hole through which the air came out compressed and with greater force. It might be necessary to use eight, ten or twelve at once according to the furnace. They walked round the fire blowing. . Nor had they tongs for getting the metal out of the fire'.

Although Garcilaso was writing specifically about Andean silversmiths, the technology he describes was widespread in South and Central America.

\section{Metals and Alloys}

Indian jewellers worked gold, silver, copper and various alloys of these metals. The first recorded analysis of an American gold ornament was made in Spain on a specimen which Columbus brought back from the island of Hispaniola. The result was disappointing: the object contained only 18 parts of gold to 6 of silver and 8 of copper. This gold-copper alloy, known as tumbaga or guanin gold, is characteristic of jewellery made in Mexico, the Isthmus and the northern Andes. In these regions the silver - which may constitute up to 25 per cent of the total weight - was not added intentionally as was the case for the copper but was present as a natural impurity in the gold. Further south, in Ecuador, Peru and Bolivia, where the production of silver always outstripped that of gold, alloys to which silver had been deliberately added were in common use and these often contained only a small percentage of gold.

As a metal for casting, tumbaga offers certain advantages. Not only is it harder than pure gold, but it is easier to cast than any of its constituent metals alone and it reproduces fine decorative detail more accurately. The alloy containing 20 per cent copper with 80 per cent gold melts at $911^{\circ} \mathrm{C}$, which is well below the melting point of pure gold $\left(1064^{\circ} \mathrm{C}\right)$ or that of copper $\left(1084^{\circ} \mathrm{C}\right)$. With appropriate surface treatment, tumbaga jewellery can be made to look like pure gold and laboratory analyses have shown that everyday tools, such as awls, axes, chisels and fishhooks made of this alloy were normally finished by cold hammering to give a working edge nearly as hard as cold-worked bronze.

\section{Sheet Metal}

Since alluvial gold usually occurs in the form of specks or small nuggets, the first stage in making any large sheet item was to prepare an ingot of cast metal by the process described in Garcilaso's account. Alloying was also carried out at this stage. Analysis of archaeological specimens from the north coast of Peru 


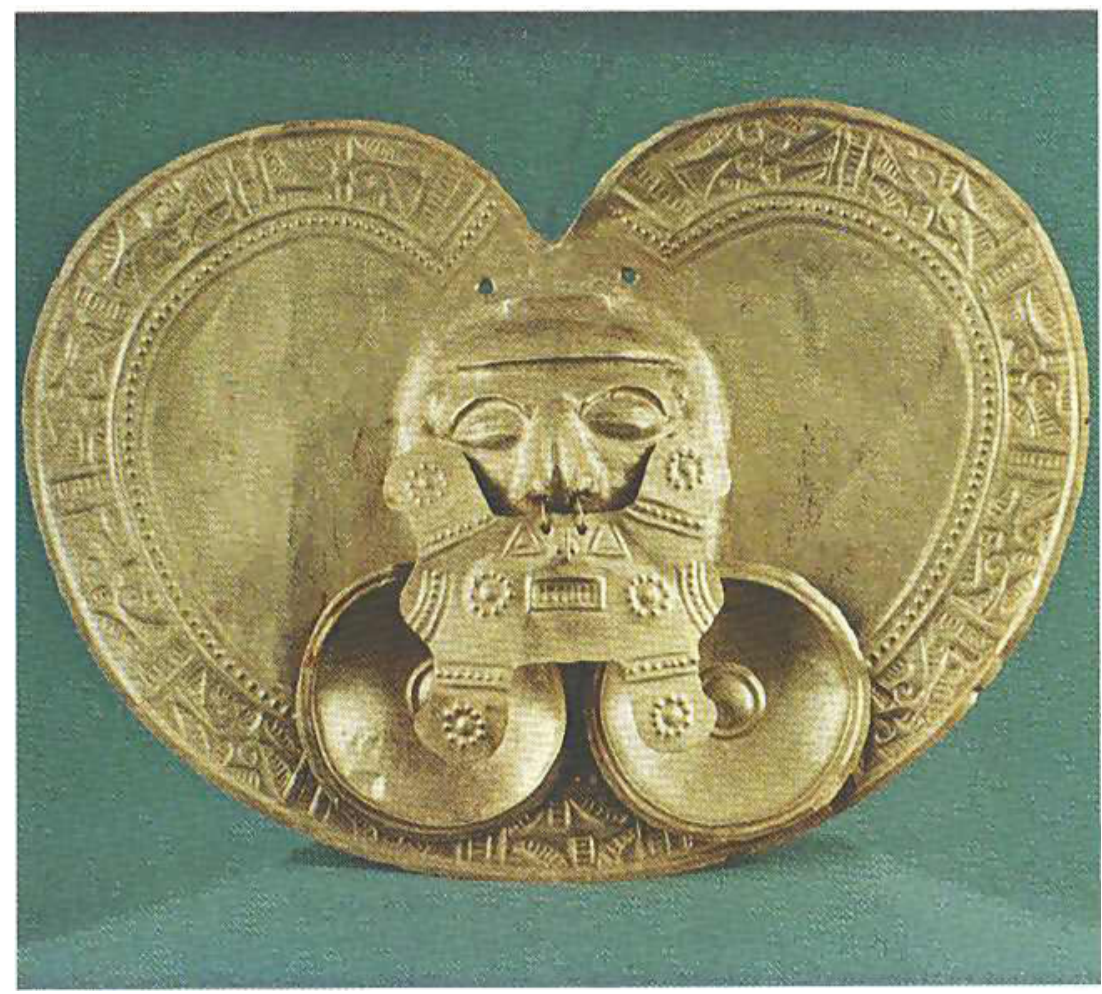

Breast ornament, with a human face wearing ornaments in the ears and nose. This large piece, $28 \mathrm{~cm}$ across, is from the Calima region of the Colombian Andes and illustrates most of the techniques used in sheet metalwork. A cast ingot (71 gold/22 copper per cent) was hammered out into heavy sheet, onto which the outline was scrib. ed and then cut out. The face was made by hammering over a model and the repoussé detail added by freehand embossing from the reverse. The ear discs and nose dangler were made separately and were attached by staples of hammered wire

Museo del Oro, Bogotá, No. 19; photograph UNESCO

shows that in this area the preferred alloy was a mixture of gold, silver and arsenical copper and that the resultant metal was worked by alternate hammering and annealing into sheet $0.2 \mathrm{~mm}$ thick, the perfect evenness of which compares well with that of today's machine-made product.

Annealing was an essential part of the process. Pure gold is soft and relatively easy to beat but under repeated hammering the alloys work-harden. The metal becomes springy and difficult to work and finally turns brittle. To restore malleability the metal must be annealed - replaced in the furnace and brought to red heat - after which it can be worked further. In the Archive of the Indies, Seville, is a document of 1555 describing the use of this technique by the Indians of Tamalameque, in lowland Colombia:

$\because$. and in this way, placing it [a bracelet] in the fire, taking it out and putting it in water, and hammering it on an anvil with the stone described, they worked until they increased its size many times'.

This practice of water quenching after annealing is significant in the light of present day knowledge of ordering and age-hardening phenomena in goldcopper and gold-silver-copper alloys.

With the ternary gold-silver-copper alloys of Peru, repeated heating and annealing operations have the effect of depleting the copper content at the surface. The copper present in the superficial layers of the sheet becomes oxidised and the resultant dark scale of copper oxides can be removed by pickling with a mild acid, such as urine or plant juices, to leave a gold- and silver-enriched surface. By a further process of depletion gilding (described below), most of the silver can in turn be removed to produce the surface appearance of almost pure gold.

In contrast to the sophisticated chemical and metallurgical knowledge shown in the preparation of metal sheet, the techniques used to fabricate the objects themselves were simple and often rather crude. An outline drawing was scribed on the sheet, sometimes with the aid of a template, and the shape was cut out with a narrow-bladed chisel. The virtue of hammered sheet is that it gives a large surface area (and therefore the maximum amount of show and glitter) for a relatively small mass of precious metal. For decorative purposes, but also to add strength to large objects made of flimsy sheet, the metalsmiths embossed repoussé designs from the rear, with the object resting on a bed of some yielding material.

The West Indian version of this technique is described in a letter written to the authorities in Seville by a certain Dr. Chanca, physician to Columbus' fleet on its second voyage of 1493 to 1496 :

'These Indians beat their gold into very thin sheets. . setting it in bitumen which they prepare for the purpose. They could not make their masks without it. They also shape gold to be worn as head ornaments, or in the ears or nose. It always has to be beaten thin, since they do not prize it as riches but only for its ornamental use'

In parts of South America, techniques of mass production were employed to make matching sets of 
identical objects by hammering thin sheet over patterns made of wood, stone or metal, or else by pressing it into hollow, intaglio-style matrices. Bowls and cups were made by 'raising'. Starting from the base, a flat disc of sheet was hammered with constant turning over a horizontal stake or a series of anvils, so that the metal was simultaneously thinned and forced upwards and outward. Further decoration could later be added by chasing designs on the surface or by attaching appliqué elements that were pressed out in large quantities with the aid of hollow matrices.

More complex shapes such as figurines or the flasks used to hold the powdered lime that was chewed with coca leaves, were also produced by joining several previously shaped pieces of sheet metal by welding, soldering or brazing (2). Mechanical methods for producing composite pieces included pinning, stapling, lacing with thin and pliable metal strip, clinching (that is, folding over and crimping into place) and a tab-and-slot technique like that used in children's cardboard models.

\section{Casting}

Simple shapes, such as axes and chisels, were often cast in open single-piece moulds made of stone or terracotta but for the more intricate forms it was necessary to use complex moulds of two or more segments. No complete set of this kind has been found archaeologically but the finished objects sometimes reveal the technique used for their manufacture in the form of a raised casting seam, where a little waste metal ran into the joins between the segments of the mould and was not completely burnished away. Although never common, the use of multiple moulds is documented from Chile, Argentina, Peru and Colombia.

More frequently, cast objects were made by the cire perdue or lost wax process, described in detail by Bernardino de Sahagún (3), an early missionary friar, in his 'General History of the Things of New Spain' written in Mexico around 1565. For hollow objects the goldsmith first prepared a mixture of potter's clay and pulverised charcoal, sometimes with the addition of a little sand. A mixture of this kind has certain essential qualities. It withstands the temperature of the molten metal without distorting, is elastic enough to allow for the shrinkage of the metal during cooling, is porous enough to take up some of the gases formed within the casing when the metal is poured and it is friable enough to break up easily for removal afterwards. At just the same time some goldsmiths in Europe were using a mixture of clay and bone meal, which has similar properties.

The core was next carved into the shape of the object to be reproduced in metal and was left to dry in the sun for two days. This prolonged drying was

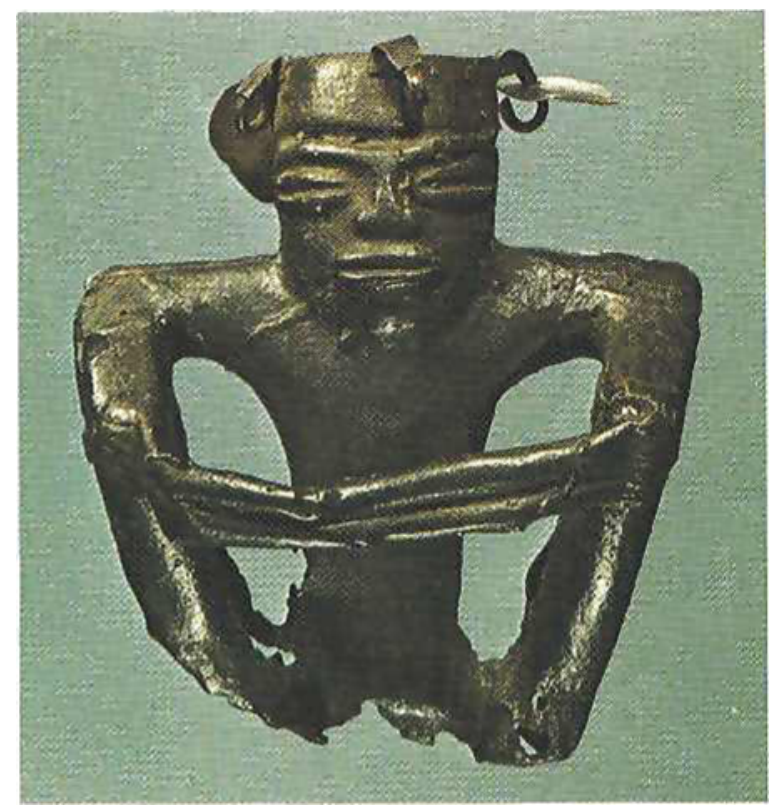

Figure from the Muisca area of Andean Colombia, hollow cast by the lost wax process. This example is of copper but the identical technique was used for gold. It still contains its original black core, which proved to be a mixture of clay and about 13 per cent wood charcoal - sufficient to give a radiocarbon date of $1055 \pm 59$ A.D. Over the core were laid strips of wax sheet, whose outlines and occasional creases are still visible in the cast metal. The face was made by pressing wax sheet over a stone matrix or template of the kind shown in the next illustration

Cambridge University Museum of Archaeology \& Anthropology; photograph Institute of Archaeology, London

needed to drive out all the moisture and to minimise the risk of explosion during casting. The goldsmith then took molten beeswax, mixed it with a little copal resin (a hardening agent), strained and purified it and rolled it out into thin sheet. This wax sheet was laid over the core and pressed against it, to follow the shape exactly. At this stage any final incised or appliqué details were added.

To give additional sharpness to the casting, the wax model was brushed with a suspension of finely powdered charcoal in water - an aboriginal American equivalent of the 'mould wash' of water glass and graphite used in modern precision casting. Further layers of semi-liquid clay were brushed on, so that even the smallest spaces in the wax were filled,and the whole model was enveloped in a thick casing of clay and coarsely ground charcoal. The internal core was held in place by pegs of green wood which passed through the wax, leaving holes in the metal casting. These holes were afterwards plugged and burnished but their position can often still be recognised on the finished item. For large complex castings, vent holes pierced the outer casing at various points, allowing gases to escape and preventing the formation of air pockets or bubbles in the metal which would spoil the product. 

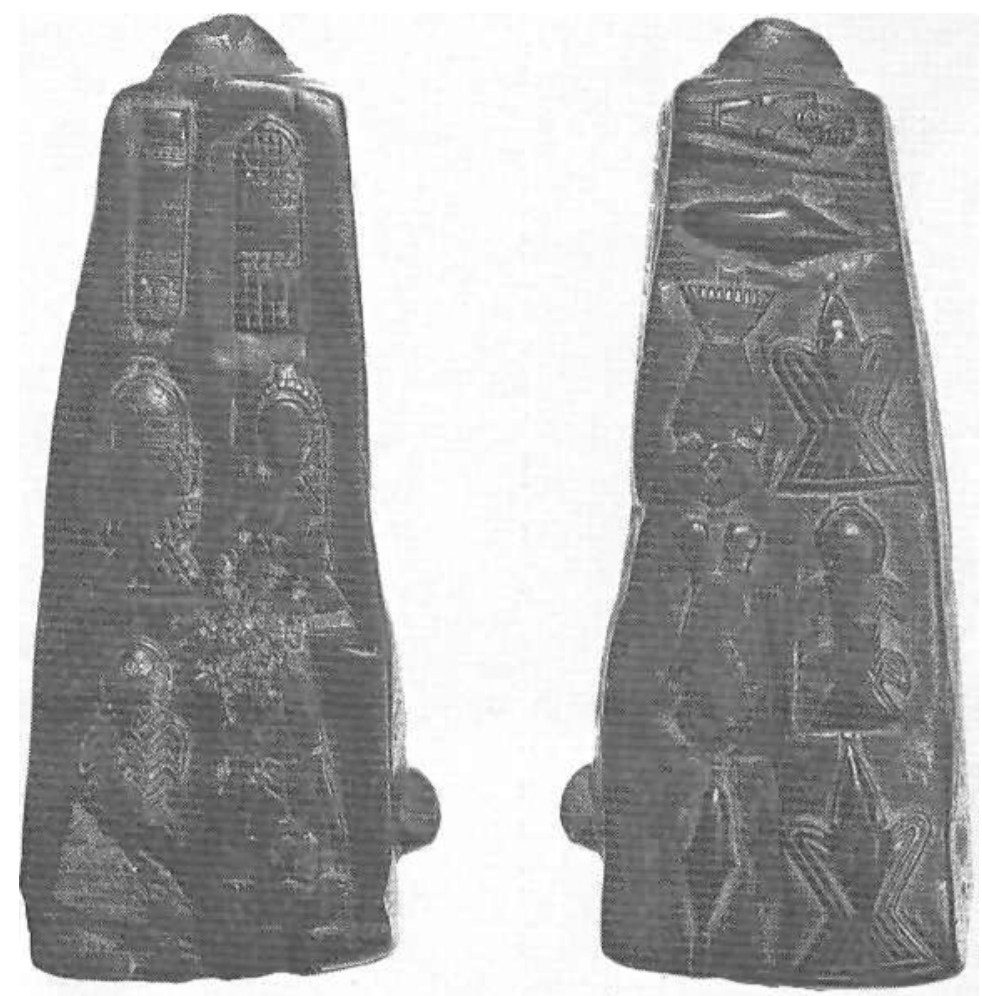

During the final centuries before the Spanish conquest, the Muisca people of the high Andes of Colombia had perfected a method of mass producing sets of identical cast elements for necklaces and figurine parts. Wax sheet was pressed over stone matrices carved in high relief and the resultant wax models were cast in the usual way. These matrices were carved on all sides and provide 'pattern books' of the most common Muisca forms (6). The illustration shows two faces of the same object. Length about $13 \mathrm{~cm}$

Staatliche Museum für Völkerkunde, Munich

The mould was now ready to be heated, in order to melt out the wax and to leave a space between the core and the outer casing. While the mould was still hot (to ensure that the metal would not set before flowing to all parts of the cast) molten gold was poured in to take the place of the melted wax. After cooling, the casing had to be broken to extract the finished article. The lost wax technique gives an exact copy of even the most delicate wax model, and because the casing has to be broken to remove the content, each item is an original creation.

Many of the objects produced in this way are small ornaments but some single-piece castings can be very large - notably the vessels manufactured in the Quimbaya zone of the Colombian Andes. Describing the tribes of the province of Anserma, Jorge Robledo remarked that 'they drink out of golden goblets, some of which weigh 300 castellanos ... and their spoons and vessels are of gold'. Since a castellano was approx. imately $4.6 \mathrm{~g}$ of gold, this corresponds to a mass of some $1400 \mathrm{~g}$, which is corroborated by actual museum specimens weighing a kilogram or more.

A few cast objects were bimetallic. In his 'History of the Indians of New Spain', Toribio de Motolinía wrote of the Mexican jewellers:

"... they can cast a bird whose tongue, head and wings move, and they can mould a monkey or other monster which moves its head, tongue, hands and feet, and in its hands they put little implements so that the figure seems to be dancing with them What is even more remarkable, they can make a piece half in gold, half in silver, and cast a fish with all its scales, in gold and silver alternating'
There is a persistent legend that Benvenuto Cellini, one of the greatest goldsmiths of the Renaissance, wasted several frustrating months trying without success to copy the process in his workshop.

A few of these bimetallic objects have survived. Those from Peru were usually made by welding together the gold and silver elements, but in Mexico the technique of 'casting on' was also employed. López de Gómara's 'History of the Conquests of Hernando Cortes' indicates that the two metals were not soldered but cast, 'adhering together in the casting'. This technique involves multiple casting and is based on the difference between the melting points of the two metals or alloys. The gold part of the object was cast first, since this metal has the higher melting point, and the craftsman then built onto it a wax replica of the silver portion. The whole preparation was then encased in fresh clay. As in ordinary lost wax casting, the wax was melted out and the molten silver was then poured in to take its place. The temperature of this second casting was lower than that of the first, so that the gold remained solid while the liquid silver flowed against it. At the interface, some alloying took place and a strong join was established.

At first glance, some archaeological items seem to have been made by the filigree process in which pieces of coiled or twisted wire are soldered to each other, or onto a back plate. Closer examination shows that most of these specimens are 'false filigree' and 


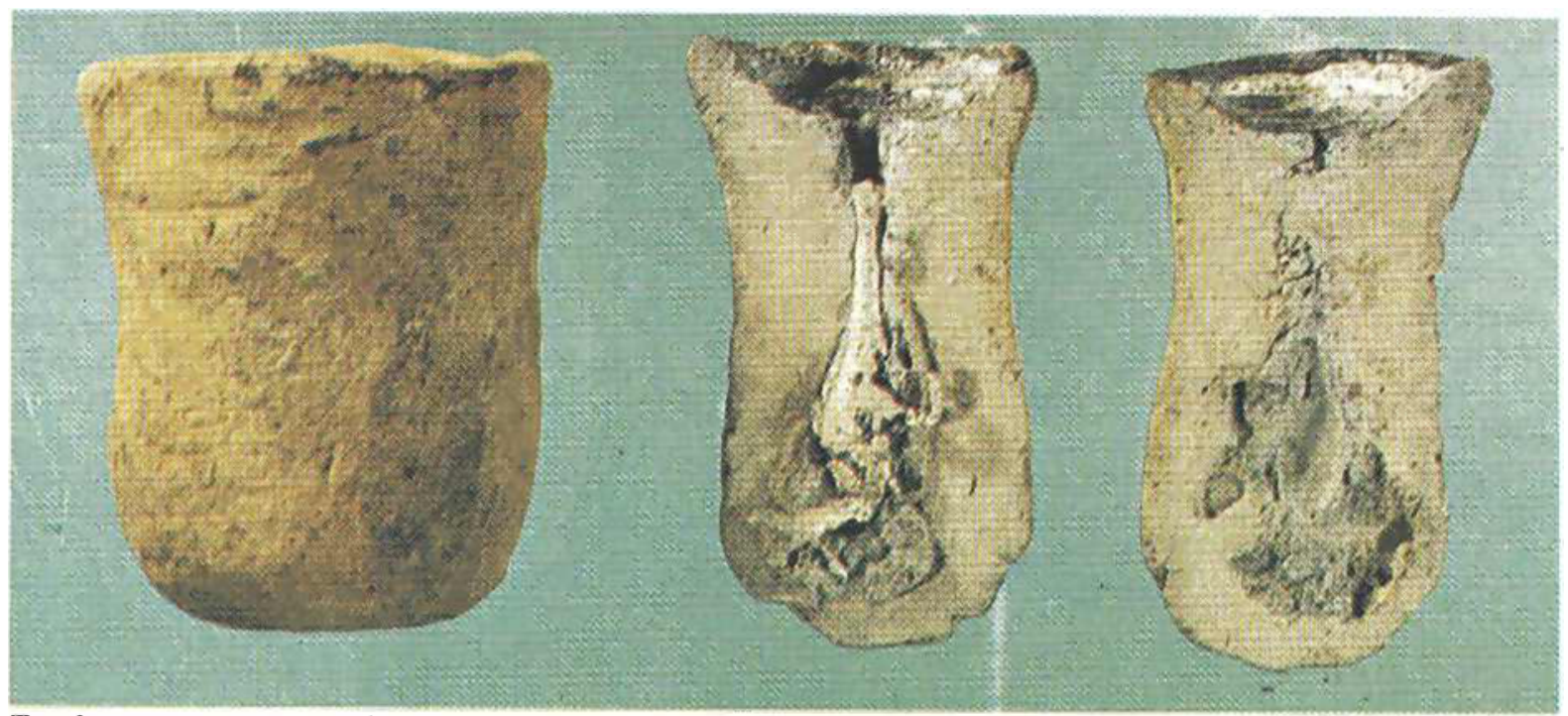

Two lost wax casting moulds from a goldsmith's tomb at Aguamona, Restrepo, in the Calima region of the Colombian Andes. One casing is untouched, and its content still unknown. The other has been re-cast in the laboratory, and cut open to show the little animal inside, the section through the reservoir and the pouring channel. A button of gold, which remained in the cup-shaped reservoir, has been removed. The height of the complete mould is $6 \mathrm{~cm}$

Museo del Oro, Bogotá; photograph Institute of Archaeology, London

were not soldered but cast in one piece. Thin wirelike wax threads were obtained, perhaps by extruding molten wax through a fine nozzle into cold water, and these threads were used to build up a wax model that was cast in the normal way.

\section{Granulation}

The method used in Ecuador and Colombia seems to be the one employed by the ancient civilisations of the Old World and which was rediscovered in Europe less than fifty years ago (2). A copper compound such as copper hydroxide or acetate was mixed with glue and was used to bond fine globules of gold into place. When the object thus assembled was heated in the reducing atmosphere of a charcoal fire, the glue was burnt away and a natural brazing alloy of gold and copper was formed, which resulted in metallic bonding at the point of contact.

\section{Gilding}

Simple shapes, such as nose rings, were sometimes covered with gold foil but more often some kind of 'depletion gilding' was employed to produce a pure gold finish on a tumbaga ornament by removing the base metals at the surface. In contrast to plating, which involves the addition of fresh material, in 'depletion gilding' all the gold is an original constituent of the alloy.

For Caribbean South America, Spanish chronicles refer to a mise-en-couleur process in which the surface of the object is depleted of copper with the aid of an acid plant juice. The document of 1555 , which has already been quoted, describes a method in use among the Indians of Tamalameque. In gilding a tumbaga piece,

'... the herb they brought to give it colour was crushed on a stone, and once crushed in this way they placed it in a small pot which they brought in, and added water and ground white salt and stirred all together"

After polishing, heating and quenching it in the solution several times, 'in this way it attained the colour and finish it should have'.

Oviedo, in Hispaniola, tried to learn the technique but notes with regret:

'I saw the herb, and the Indians taught me about it, but I was never able by flattery, or in any other way, to get the secret from them. They denied that they practiced it, saying that it was carried out in other lands far away, pointing to the south'

For ternary alloys with a low gold content, the technique of 'superficial parting' was preferred. Sahagun describes the use of a 'gold medicine' which looked like yellow earth mixed with salt and he is probably referring to a naturally occurring corrosive mineral - perhaps one of the hydrated ferric sulphates. The method by which Peruvian jewellers produced a superficial layer of gold on their silverrich alloys has been replicated in the laboratory by Professor Heather Lechtman of the Massachusetts Institute of Technology (4). The object was first coated with a paste of alum, common salt and potassium nitrate or some other corrosive mineral. After heating, this paste was washed off and the thin black scale left on the surface was removed with a hot, strong salt solution. As the final step, the gold particles at the surface were consolidated by moderate heating followed by burnishing with a stone or a piece of cane. By covering only a portion of the surface with 
paste, the American goldsmiths were able to produce designs of contrasting colours.

\section{Workshop Sites}

Although the number of archaeological specimens available for study is enormous (the Gold Museum in Bogotá, Colombia, has a collection of some 28000 pieces) the workshop sites where these items were produced have still to be found and investigated. These sites undoubtedly exist. They are described in general terms by Spaniards who visited them and there are many tantalising reports of discoveries made before the days of scientific archaeology. The following account, which is fairly typical, comes from the memoirs of Luis Arango, a famous figure in the history of guaqueria (tomb-robbing) in Colombia:

'At $15 \mathrm{~km}$ from Amalfi was an Indian site measuring about 20000 square varas. The earth of this site was washed and panned in 1851. It is said that it yielded not less than $20 \mathrm{ar}$. robas [about $230 \mathrm{~kg}$ ] of gold in the form of trimmings, scraps, drops of melted gold, etc. There were also remains of what seemed to be an ancient foundry. The principal finds included five perfectly round balls of fine gold, four smaller ones a little under the size of a hen's egg, and another as big as a billiard ball.... Among the slag and debris were pieces of wood charcoal, many fragments of pottery, and various broken crucibles made of clay. These crucibles were the size and shape of half an orange, and on the rim of each crucible were two projections about 4 inches long'.
This site has never been rediscovered, nor has any pre-European workshop been excavated by trained archaeologists. One is therefore forced back on inferences drawn from museum specimens.

Some of the most complete information comes from the Esmeraldas region of north coastal Ecuador. By panning the sands and gravels at La Tolita, treasurehunters have recovered thousands of small objects washed out from destroyed archaeological sites. The material includes pieces of melted gold, packages of hammered foil and also lumps of alloy made from remelted scrap metal. One such lump still has an imperfectly fused piece of copper encased in the gold. Several specimens showed the clear imprint of woodgrain, suggesting that small fragments of metal were fused, with the aid of a blowpipe, in a hollow scraped in a charcoal slab.

Tolita smiths worked with copper, gold, tumbaga, lead and - more remarkably - with platinum, which occurs in the gold-bearing sands of the Pacific coast rivers, but was not recognised as a separate metal in Europe until 1748. Because of its high melting point $\left(1769^{\circ} \mathrm{C}\right)$ it was impossible for the Ecuadorian craftsmen to melt the platinum but they sidestepped the problem by sintering it with gold. The platinum grains were mixed with a little gold dust and the mix-

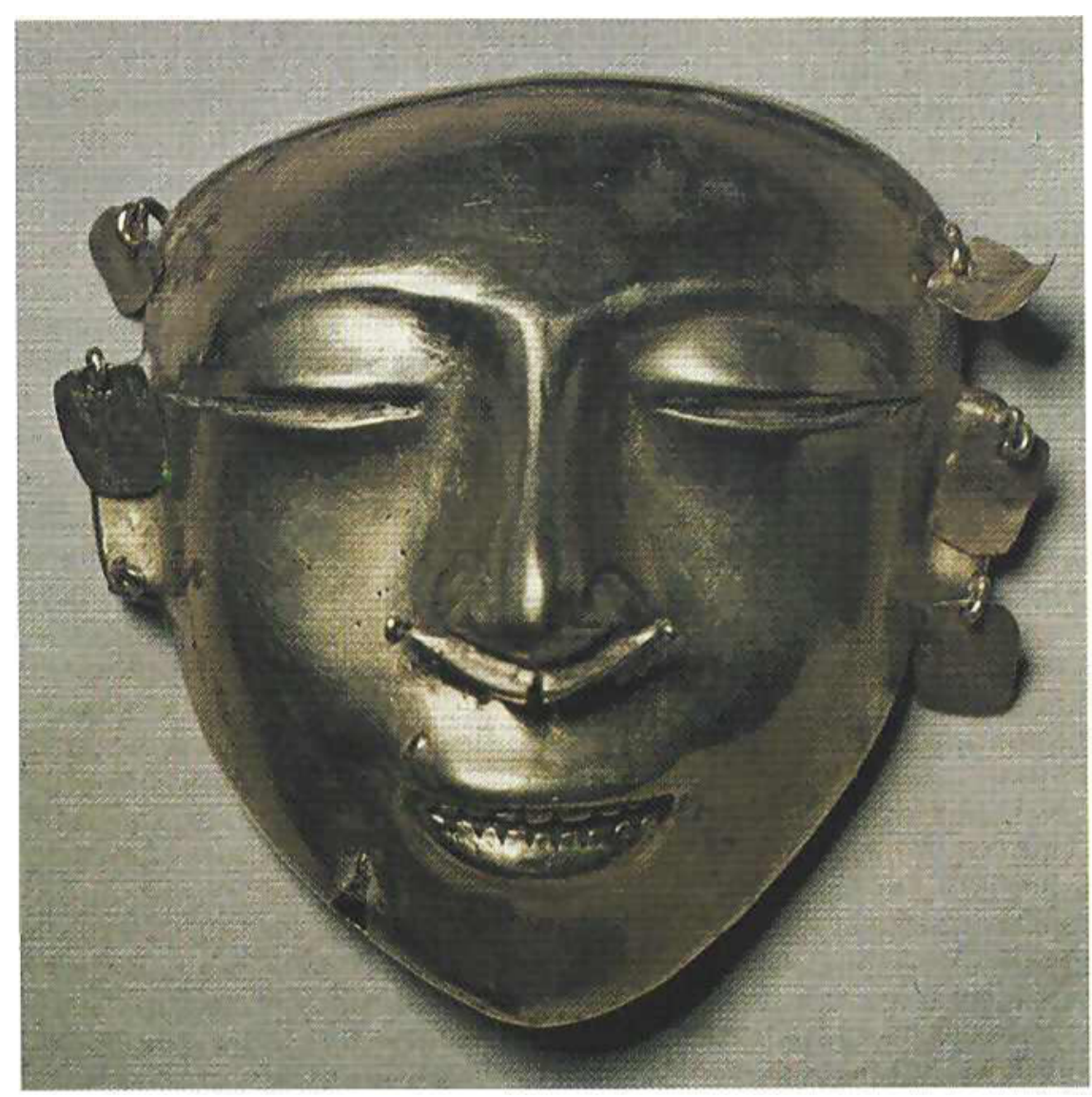

Gold mask, $11.5 \mathrm{~cm}$ high, cast by the lost wax process. Traces of black mould materials still remain on the reverse and in the hollows of the ears. A casting flaw on the side of the chin has been partly repaired by running in fresh metal. Quimbaya region of Andean Colombia Museum of Mankind, London; photograph Jorge Nieto 


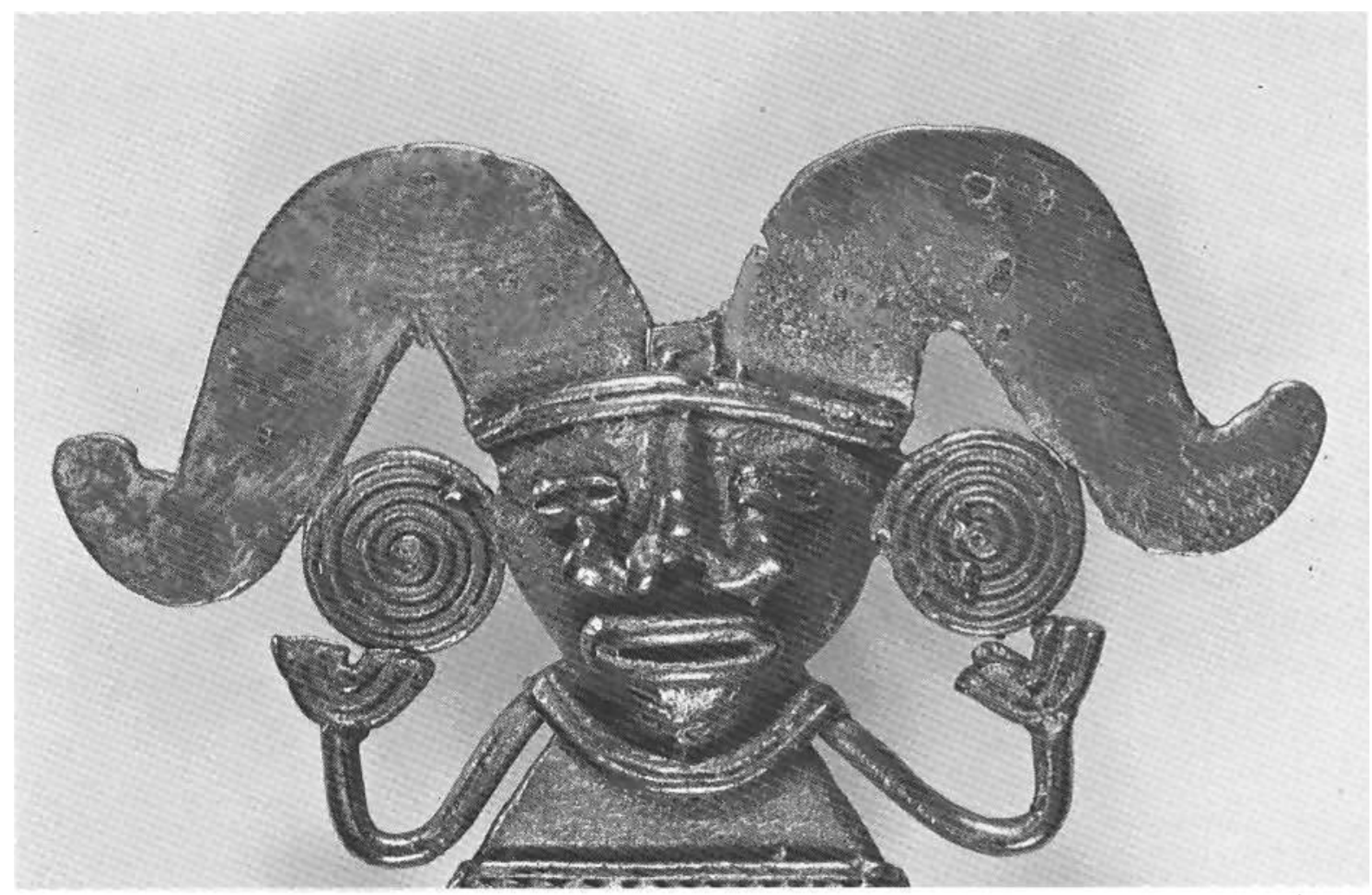

If the wax model for casting is not completely smoothed, it may still show the fingerprints of the goldsmith. These will then be faithfully reproduced on the finished metal piece, as on the headdress of this example. The presence of such fingerprints led to a persistent belief (often quoted in nineteenth century popular literature) that the Indians had discovered the secret of softening gold so that it became malleable like clay and could be manipulated by hand. Sinú region of northern Colombia

Museo del Oro, Bogotá, No. 25.132

ture was heated until the gold melted and flowed, binding the granules of platinum together. By repeated hammering and heating, this compound was consolidated into a homogeneous mass that could be forged and cast, even though the platinum never actually melted. The process is a remarkable anticipation of a basic principle of modern powder metallurgy - the sintering and incipient fusion of refractory metals.

These precocious developments of platinum technology serve as a reminder that jewellery is a craft which relies on human skills rather than on machinery. Perhaps the most appropriate epitaph for the anonymous Indian goldsmiths of America comes from Peter Martyr, historian and member of the Council of the Indies. Like Dürer, Martyr saw Montezuma's treasure in Brussels and afterwards wrote in a report to Pope Leo X:

'But surely, if ever the wits and inventions of men have deserved honour or commendation in such arts, these seem most worthy to be held in admration. I do not marvel at gold and precious stones, but I am in a manner astonished to see the workmanship excel the raw material. For I have with wondering eyes beheld a thousand forms and similitudes of which I am not able to write. And, in my judgment, I never saw anything whose beauty might so allure the eyes of men'.

\section{References}

1 J. R. Fisher, Gold Bull., 1976, 9, (2), 58-63

2 P. M. Roberts, Gold Bull., 1973, 6, (4), 112-119

3 D. T. Easby, Univ. Mus. Bull. Univ. Pennsylvania, 1965, 5, (4), 3-15

4 H. N. Lechtman, in 'Science and Archaeology' ed. by R. H. Brill, M.I.T. Press, Cambridge, Mass., 1971, 2-30 and in 'Application of Science in Examination of Works of Art', ed. by W. J. Young, Museum of Fine Arts, Boston, Mass., 1973 $38-52$

5 C. Donnan, Archaeol., 1973, 26, (4), 289-297

6 I. von Schuler-Schömig, Baessler Arch., 1974, 22, 1-22 